\title{
Hybrid Optimization Strategy using Response Surface Methodology and Genetic Algorithm for reducing Cogging Torque of SPM
}

\author{
Min-Jae Kim ${ }^{\dagger}$, Jaewon Lim*, Jang-Ho Seo* and Hyun-Kyo Jung*
}

\begin{abstract}
Numerous methodologies have been developed in an effort to reduce cogging torque. However, most of these methodologies have side effects that limit their applications. One approach is the optimization methodology that determines an optimized design variable within confined conditions. The response surface methodology (RSM) and the genetic algorithm (GA) are powerful instruments for such optimizations and are matters of common interest. However, they have some weaknesses. Generally, the RSM cannot accurately describe an object function, whereas the GA is time consuming. The current paper describes a novel GA and RSM hybrid algorithm that overcomes these limitations. The validity of the proposed algorithm was verified by three test functions. Its application was performed on a surface-mounted permanent magnet.
\end{abstract}

Keywords: Response surface methodology, Genetic algorithm, Hybrid optimization

\section{Introduction}

Cogging torque is produced by the interaction between the electric motor magnets and the stator slots within permanent magnet motors. If the cogging torque is large, torque ripples correspondingly become large, making motor control difficult [1]. Thus, it is an important factor in the design process of permanent magnet motors.

Many methodologies exist endeavoring to reduce cogging torque. However, these methodologies usually result in the overall reduction of the average torque. Thus, great care should be taken in the investigation of reducing cogging torque without a significant reduction in the average torque. In previous cogging torque reduction studies, the focus is usually on comparing the genetic algorithm results with the response surface methodology (RSM) results [2-4]. According to the comparison, GA results are observed to be more exact than those of the RSM. However, the GA requires more time.

In this study, we present a hybrid optimization algorithm combining the desirable aspects of the GA and the RSM. The hybrid algorithm is able to determine a solution within a smaller region than in the region exercised only by the GA, thus consuming less time. Moreover, the hybrid algorithm determines a more precise solution than the RSM.

The design factors of surface-mounted permanent magnet (SPM) electric motors are considered in this research. The main objective is to maximize cogging torque reduction while maintaining average torque.

$\dagger \quad$ Corresponding Author: School of Electrical Engineering and Computer Science, Seoul National University, Korea. (haemish@hanmail.net)

* School of Electrical Engineering and Computer Science, Seoul National University, Korea. (hkjung@snu.ac.kr) Received: March 14, 2010; Accepted: December 1, 2010

\section{Proposed Algorithm}

\subsection{Concept of the Proposed Algorithm}

The hybrid algorithm executes the GA and RSM simultaneously. Calculating all design variables within each available region is a very difficult task. Thus, the hybrid algorithm uses only several regions of the design variables to infer the object function. The general sequence of the hybrid algorithm is as follows: perform RSM in the initial search region, set a new search region, and then apply the GA in the new search region as shown in Fig. 1.

Unlike the GA, the hybrid algorithm uses a new search region. The new search region is a search region with a reduced size; it is where finding the optimal value is performed. Its size is set to almost half of the initial search region. The new search region center is determined by the RSM summit.

Designing an optimal motor using the RSM has been greatly investigated in both past and present studies $[3,5$,
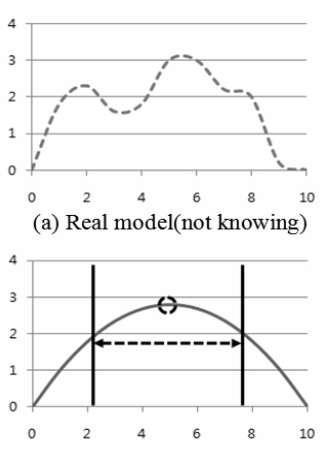

(c) Making a new search region
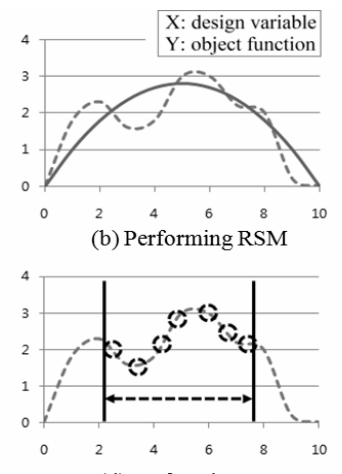

(d) Performing GA

Fig. 1. Optimization flow of the hybrid algorithm. 


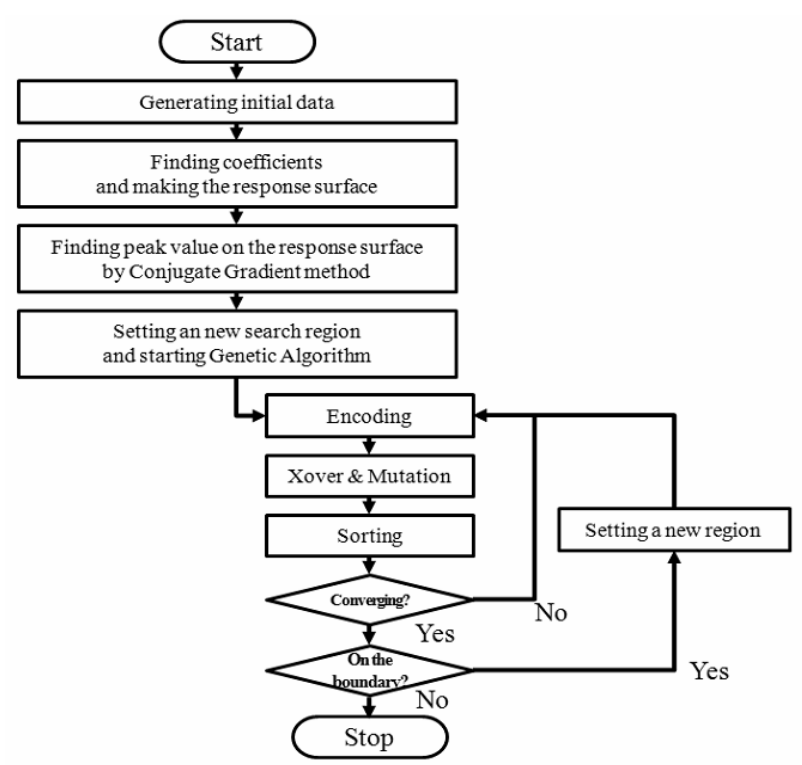

Fig. 2. Basic steps of the hybrid algorithm.

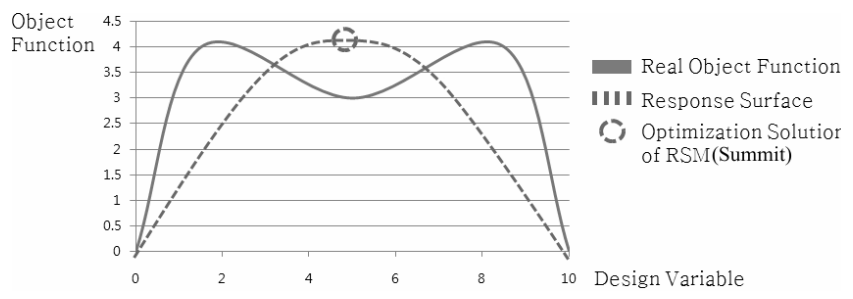

(a) RSM optimal solution of exceptional case

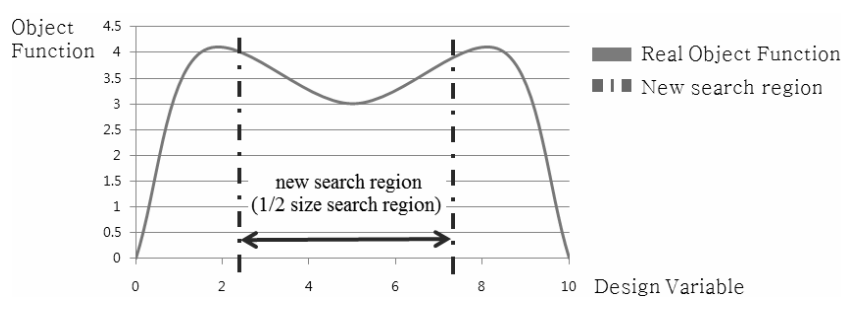

(b) New searcg reguib if exceptional case

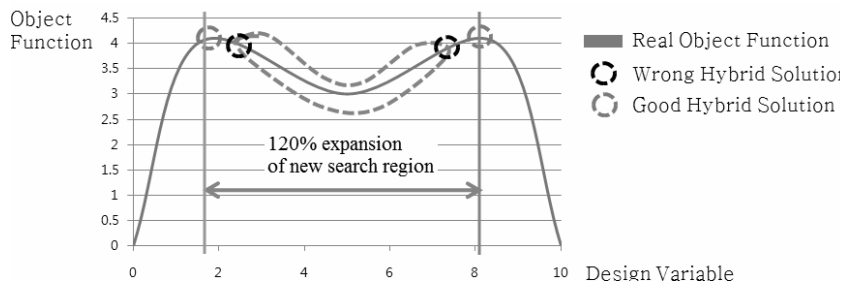

(c) Exoabded bew searcg region

Fig. 3. Exceptional case treatment of the hybrid algorithm.

6]. Focusing on the RSM optimization region, exploring half of the RSM region is reasonable [6]. However, some exceptional cases exist, as shown in Fig. 3. These cases occur when the object functions have multi-peaks. Treatments to such cases are presented in this study.

\subsection{Basic Steps of the Proposed Algorithm}

The algorithm used for the present investigation is a GARSM hybrid, which performs faster and produces more precise results than the previous algorithms. The basic steps of the proposed algorithm (hybrid algorithm) are described in sequence as well as illustrated in Fig. 2.

Step 1: Sample the finite element method (FEM) results for the Central Composite Design of the Design of Experiments.

Step 2: Determine the surface response from Step 1.

Step 3: Find a summit on the response surface via the conjugate gradient method.

Step 4: Assign a new search region that is half the area of the original region in Step 1. The new search region center is the same as the design variable coordinates of the summit in Step 3.

Step 5: Perform the GA in the new search region.

Step 6: Perform the GA again if the final result is on the boundary (exceptional case treatment).

\subsection{Exceptional Case Treatment}

When limiting the search area to almost half of the RSM regions, as in the case shown in Fig. 3, a possibility exists that the real optimal solution may be neglected if the real solution is not near the RSM optimal solution. To avoid such exceptional case, the hybrid optimizing algorithm uses an expanded exploration region and explores $120 \%$ of the area of the new search region. Fig. 3 shows the sequence of finding a real object function in such an exceptional case.

\section{Proposed Algorithm Test}

The hybrid algorithm was verified by three test functions. To evaluate the performance, the result was compared with that obtained using the GA. The convergence of the GA and the hybrid algorithm was determined by the elite root convergences generated in each generation. To reduce deviation, test calculations were performed 10 times. Moreover, the average of the FEM calculation number was selected as the resultant call number until convergence occurred.

\subsection{Case 1}

Fig. 4 shows a test function using Eq. (1), which represents a real equation for the test function 1. Table 1 shows the results using both the GA approach and the proposed hybrid algorithm approach. The table indicates that, on average, a $19 \%$ calling number reduction was achieved using the proposed algorithm.

$$
z=\sin (x+y)+1-\frac{x^{2}}{40}+\exp \left(-y^{2}\right)
$$




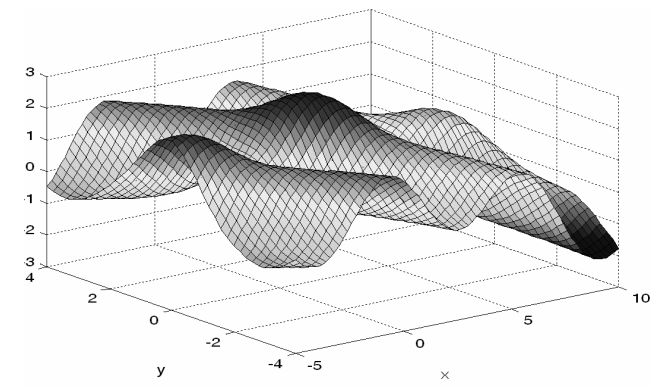

Fig. 4. Test function 1.

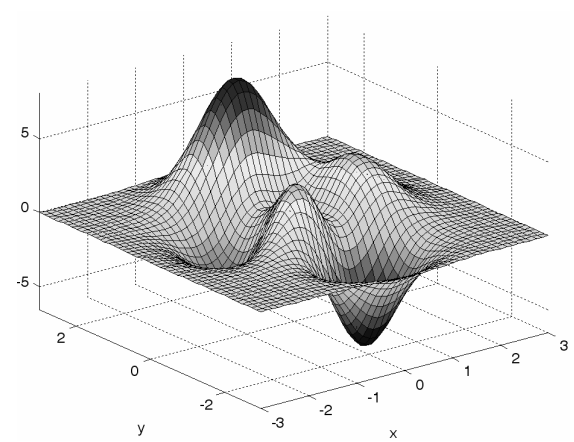

Fig. 5. Test function 2 .

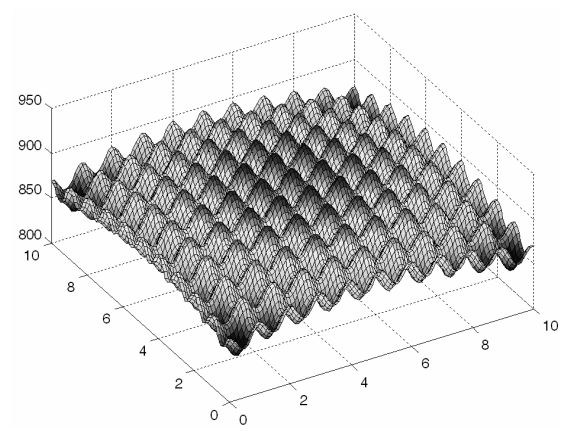

Fig. 6. Test function 3 .

Table 1. Test function 1 comparison between the GA and the hybrid algorithm

\begin{tabular}{c|c|c}
\hline Sequence & $\begin{array}{c}\text { GA until } \\
\text { convergence }\end{array}$ & $\begin{array}{c}\text { Hybrid algorithm } \\
\text { until convergence }\end{array}$ \\
\hline $1^{\text {st }}$ & 54 & 39 \\
\hline $2^{\text {nd }}$ & 84 & 54 \\
\hline $3^{\text {rd }}$ & 54 & 57 \\
\hline $4^{\text {th }}$ & 88 & 66 \\
\hline $5^{\text {th }}$ & 48 & 48 \\
\hline $6^{\text {th }}$ & 42 & 38 \\
\hline $7^{\text {th }}$ & 72 & 48 \\
\hline $8^{\text {th }}$ & 105 & 63 \\
\hline $9^{\text {th }}$ & 51 & 45 \\
\hline $10^{\text {th }}$ & 54 & 71 \\
\hline Average & 65.2 & 52.9 \\
\hline
\end{tabular}

Table 2. Test function 2 comparison between the GA and the hybrid algorithm

\begin{tabular}{c|c|c}
\hline Sequence & $\begin{array}{c}\text { GA until } \\
\text { convergence }\end{array}$ & $\begin{array}{c}\text { Hybrid algorithm } \\
\text { until convergence }\end{array}$ \\
\hline $1^{\text {st }}$ & 84 & 48 \\
\hline $2^{\text {nd }}$ & 66 & 63 \\
$3^{\text {rd }}$ & 69 & 45 \\
\hline $4^{\text {th }}$ & 69 & 48 \\
\hline $5^{\text {th }}$ & 63 & 12 \\
\hline $6^{\text {th }}$ & 81 & 21 \\
$7^{\text {th }}$ & 48 & 75 \\
\hline $8^{\text {th }}$ & 39 & 96 \\
\hline $9^{\text {th }}$ & 96 & 54 \\
\hline $10^{\text {th }}$ & 57 & 36 \\
Average & 67.2 & 49.8 \\
\hline
\end{tabular}

Table 3. Test function 3 comparison between the GA and the hybrid algorithm

\begin{tabular}{c|c|c}
\hline Sequence & $\begin{array}{c}\text { GA until } \\
\text { convergence }\end{array}$ & $\begin{array}{c}\text { Hybrid algorithm } \\
\text { until convergence }\end{array}$ \\
\hline $1^{\text {st }}$ & 404 & 153 \\
$2^{\text {nd }}$ & 522 & 148 \\
\hline $3^{\text {rd }}$ & 585 & 157 \\
\hline $4^{\text {th }}$ & 574 & 239 \\
$5^{\text {th }}$ & 391 & 439 \\
\hline $6^{\text {th }}$ & 222 & 63 \\
\hline $7^{\text {th }}$ & 360 & 388 \\
\hline $8^{\text {th }}$ & 438 & 233 \\
\hline $9^{\text {th }}$ & 984 & 172 \\
\hline $10^{\text {th }}$ & 631 & 142 \\
\hline Average & 511.1 & 213.4 \\
\hline
\end{tabular}

\subsection{Case 2}

Fig. 5 shows the test function using Eq. (2), which represents a real equation for the test function 2. Table 2 shows the results using both the GA approach and the proposed hybrid algorithm approach. The table indicates that, on average, a $26 \%$ calling number reduction was achieved using the proposed algorithm.

$$
\begin{aligned}
z= & 3(1-x)^{2} \times 2 \exp \left(-x^{2}-(y+1)^{2}\right)-10 \times\left(\frac{x}{5}-x^{3}-y^{5}\right) \\
& \times \exp \left(-x^{2}-y^{2}\right)-\frac{1}{3} \exp \left(-(x+1)^{2}-y^{2}\right)
\end{aligned}
$$

\subsection{Case 3}

Fig. 6 shows the test function using Eq. (3), which represents a real equation for the test function 3 . Table 3 shows 
the results using both the GA approach and the proposed hybrid algorithm approach. The table indicates that, on an average, a $78 \%$ calling number reduction was achieved by using the proposed algorithm.

$$
\begin{aligned}
z= & 900-(x-5)^{2}-(y-5)^{2}+10 \times \cos (2 \pi x-10 \pi) \\
& +10 \cos (2 \pi y-10 \pi)
\end{aligned}
$$

\section{Proposed Algorithm Application}

\subsection{Basic Specifications and Characteristics of the SPM}

The basic application model upon which the hybrid algorithm was tested is a three-phase BLAC SPM motor, as depicted in Table 4. Fig. 7 shows the back EMF of the basic model, illustrating a maximum voltage of $3.73 \mathrm{~V}$ at $6000 \mathrm{r} / \mathrm{min}$. Fig. 10 shows the cogging torque. The maximum cogging torque value appeared 6 times per period, and the peak to peak value was approximately $2.2 \times 10^{-2} \mathrm{Nm}$, which is about $20 \%$ of the torque average [7].

In the model, the maximum input current per phase was 10 A with 30 turns as shown in Fig. 8. Fig. 11 presents the temporal pattern of the torque ripples with the maximum input current. The torque average was approximately $1.03 \times 10^{-1} \mathrm{Nm}$.

Naturally, the motor does not operate at a full load all the time. Thus, the ratio of the cogging torque peak-to-peak value to the torque average is larger under the actual operating condition. Considering safety and the operation of the motor, this is not acceptable.

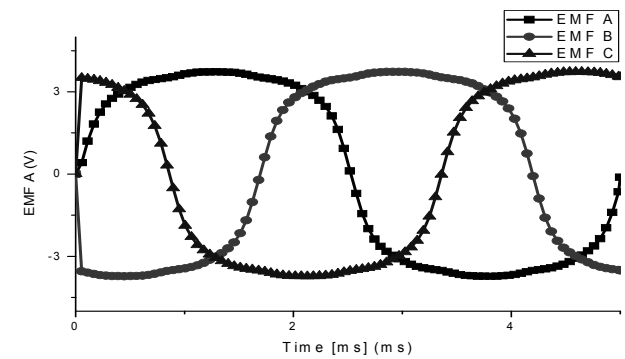

Fig. 7. Three-phase back EMF of the basic model.

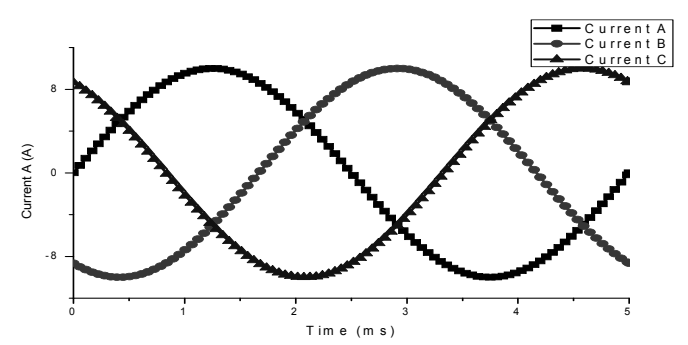

Fig. 8. Three-phase input current of the basic model.

\subsection{Design Variable and Object Function}

Cogging torque generally varies with the pole angles, air-gap length, magnetization direction, slot openings, bifurcated teeth shape, skewing, slotless armature, etc. In the current study, pole angle and bifurcated teeth diameter were selected as the design variables.

To use the hybrid algorithm, the RSM was first performed on limited design variables $x$ and $y \quad(0 \leq x \leq 4$, $0 \leq y \leq 10)$, where $x$ represents the bifurcated teeth diameter, and $\mathrm{y}$ is the pole angle. In this paper, $\mathrm{Z}$ is an object function represented by

$$
Z=\text { Torque Average }+K \times \frac{1}{\text { Cogging Torque Peak to Peak }}
$$

where $\mathrm{K}$ is a constant required for balancing the torque average $(\mathrm{Nm})$ and the cogging torque peak-to-peak $(\mathrm{Nm})$. The goal is to maximize $Z$.

To maximize $Z$, the first term and the second term in Eq. (4) must both be large. However, if we bifurcate or enlarge the pole angle greatly to produce a larger value for the second term, the output power would decrease. The torque average would decrease, indicating that the first term in Eq. (4) would be reduced, whereas the second term in Eq. (4) would increase. The reason is that the enumerator, i.e., the cogging torque, would be reduced. Alternatively, if we bifurcate or enlarge the pole angle weakly, the first term in Eq. (4) would maintain its value. However, the second term would be reduced as the enumerator, i.e., the cogging torque, would not shrink much. Therefore, maximizing $\mathrm{Z}$ is not a simple task and is determined by balancing the first and second terms of Eq. (4). When balancing the first term and the second terms, appropriately setting $\mathrm{K}$ should be the first consideration. The reason is that if we select the value of $\mathrm{K}$ inappropriately, then we can obtain the maximized $\mathrm{Z}$ with a small torque average and a small cogging torque peak-to-peak. We can also obtain a large torque average, but the cogging torque peak-to-peak will be large as well. Such cases are not acceptable.

Therefore, a criterion was developed to allow $\mathrm{K}$ to maintain the average torque level, which is $95 \%$ of the basic model, and the cogging torque peak-to-peak, which is as much as $40 \%$ of the basic model. That is, the basic model average torque was $1.03 \times 10^{-1} \mathrm{Nm}$, and the cogging torque peak-to-peak was $2.2 \times 10^{-2} \mathrm{Nm}$. The required optimized average torque was $9.8 \times 10^{-2} \mathrm{Nm}(95 \%)$, whereas the required optimized cogging torque peak-to-peak was $8.8 \times 10^{-}$ ${ }^{3} \mathrm{Nm}(40 \%)$. If the goal is satisfied, then the cogging torque peak-to-peak would be less than $10 \%$ of the average torque, whereas it would be over $20 \%$ in the basic model. Thus, the following equation was used:

$$
1.03 \times 10^{-1}+\frac{K}{2.2 \times 10^{-2}}<9.8 \times 10^{-2}+\frac{K}{8.8 \times 10^{-3}}
$$




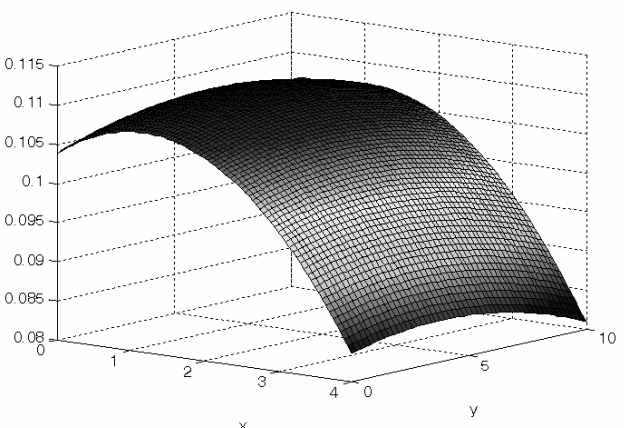

Fig. 9. Response surface of the optimized model.

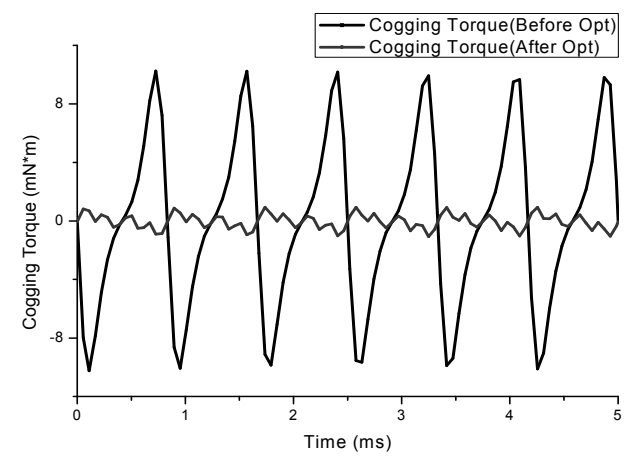

Fig. 10. Cogging torque before and after optimization.

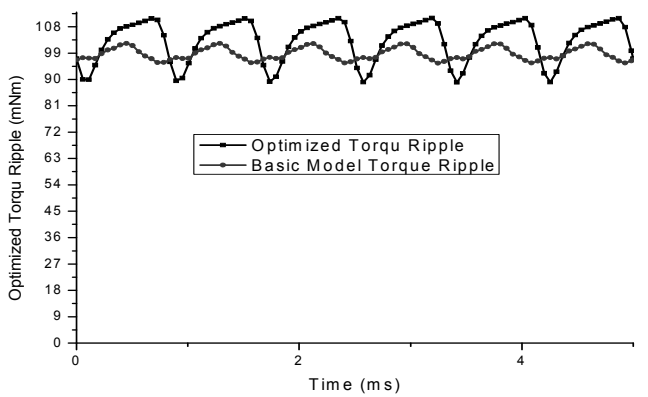

Fig. 11. Torque ripple before and after optimization.

$\mathrm{K}$, which satisfies Eq. (5), is $\mathrm{K}>7.6 \times 10^{-5}$. If we select $\mathrm{K}$ to be much greater than $7.6 \times 10^{-5}$, then the effect of the torque average becomes very small, allowing us to obtain the maximized $\mathrm{Z}$ with a small torque average. However, this result is ineffective because we do not want to reduce the torque average despite the maximized $\mathrm{Z}$. Therefore, to produce the desired results for $\mathrm{K}, 1 \times 10^{-4}$ was selected as the design value of $\mathrm{K}$ for optimization processing.

\subsection{Optimization Result}

The regression function by the RSM was determined to be

$$
\begin{aligned}
f(X, Y)= & 0.103862+0.00719426 X+0.00113873 Y \\
& -0.00305787 X^{2}-0.00013749 Y^{2}-0.0000688328 X Y
\end{aligned}
$$

The response surface derived from the RSM result is shown in Fig. 9. The summit of the response surface was found at $(X, Y)=(1.12,4.66)$ with $f(X, Y)=0.11$. Thus, the new search region used in the hybrid algorithm was established with its center at $(1.12,4.66)$.
Table 4. Basic motor specifications

\begin{tabular}{c|c|c|c}
\hline Power & $65 \mathrm{~W}$ & Phases & 3 Phase \\
\hline Current type & Sinusoidal & Max r/min & 6000 \\
\hline Height & $12 \mathrm{~mm}$ & Slots & 12 \\
Turns & 30 & Poles & 4 \\
\hline
\end{tabular}

Table 5. FEM call number comparison with the GA and the hybrid optimization

\begin{tabular}{c|c|c}
\hline & GA & Hybrid optimization \\
\hline FEM call number & 3900 & 909 \\
\hline
\end{tabular}

Table 6. Torque average, torque ripple, and cogging torque before and after the hybrid optimization algorithm

\begin{tabular}{c|c|c|c}
\hline & Basic model & Optimized model & Comparison \\
\hline $\begin{array}{c}\text { Torque average } \\
{[\mathrm{Nm}]}\end{array}$ & $1.03 \times 10^{-1}$ & $9.86 \times 10^{-2}$ & $\begin{array}{c}4.5 \% \\
\text { reduction }\end{array}$ \\
\hline $\begin{array}{c}\text { Torque ripple } \\
{[\mathrm{Nm}]}\end{array}$ & $2.19 \times 10^{-2}$ & $6.7 \times 10^{-3}$ & $\begin{array}{c}70 \% \\
\text { reduction }\end{array}$ \\
\hline $\begin{array}{c}\text { Cogging torque } \\
{[\mathrm{Nm}]}\end{array}$ & $2.2 \times 10^{-2}$ & $2 \times 10^{-3}$ & $\begin{array}{c}91 \% \\
\text { reduction }\end{array}$ \\
\hline
\end{tabular}
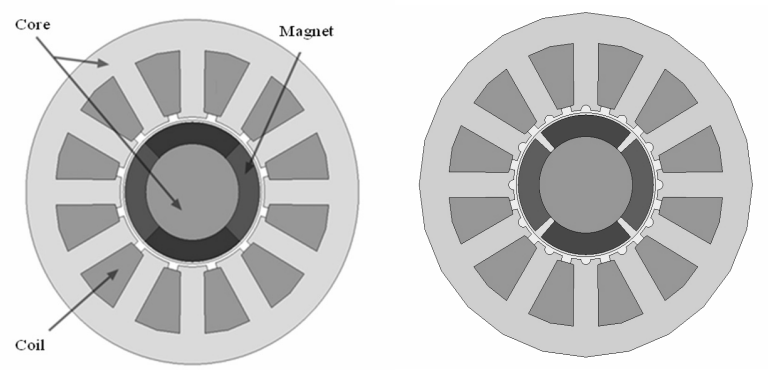

(a) Model before optimization (b) Model after optimization

Fig. 12. Shape of the model before and after optimization.

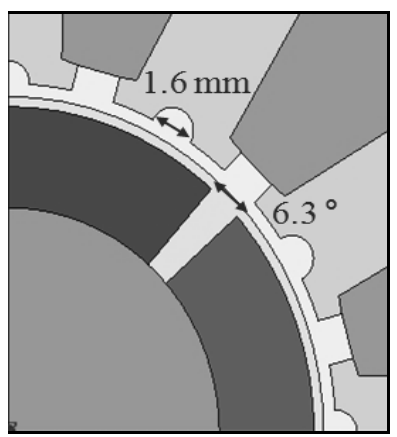

Fig. 13. Expanded view of the optimized model showing the bifurcated teeth diameter and pole angles.

The results in Table 5 were obtained using the GA. The call number reduction based on the FEM calculation counting number was as much as $74 \%$. The optimal solution was found when $\mathrm{X}$ and $\mathrm{Y}$ were $1.6 \mathrm{~mm}$ and 6.8 degrees, respectively, with $\mathrm{Z}=0.1486$. This indicates some difference with the RSM result when $(X, Y)=(1.12,4.66)$.

In Fig. 10, the cogging torque peak-to-peak value in the optimized model occurs 6 times and is $2 \times 10^{-3} \mathrm{Nm}$, which is 
about $9 \%$ of the value of the basic model $2.2 \times 10^{-2} \mathrm{Nm}$. The figure also shows a comparison of the cogging torque peak-to-peak before and after optimization.

The average torque in the optimized model is $9.86 \times 10^{-2}$ $\mathrm{Nm}$, and the torque ripple peak-to-peak is $6.7 \times 10^{-3} \mathrm{Nm}$. The torque average drops from $1.03 \times 10^{-1} \mathrm{Nm}$ in the basic model to $9.86 \times 10^{-2} \mathrm{Nm}$ in the optimized model, representing a $4.5 \%$ reduction. The torque ripple peak-to-peak drops from $2.19 \times 10^{-2} \mathrm{Nm}$ in the basic model to $6.7 \times 10^{-3} \mathrm{Nm}$ in the optimized model, resulting in a $70 \%$ reduction. This result indicates that the hybrid algorithm optimization can maintain the average torque while successfully reducing the cogging torque. A summary of the results is presented in Table 6 .

When $\mathrm{X}=1.6 \mathrm{~mm}$ and $\mathrm{Y}=6.8$ degrees, the shape of the motor is as shown in Figs. 12 and 13.

\section{Conclusion}

The current paper presented a hybrid optimization methodology capable of reducing cogging torque in an SPM motor. The methodology utilized a combination of the GA and the RSM to reduce cogging torque while the maintaining average torque. The hybrid algorithm overcame the weaknesses of the previous GA and RSM optimization algorithms. Previous methods used either the GA or the RSM; the GA usually consumes a large amount of time, whereas the RSM is not always accurate. In this paper, bifurcated teeth diameters and pole angle changes were the design variables. The object function obtained cogging torque reduction while maintaining the average torque. The hybrid algorithm flow was RSM $\rightarrow \mathrm{CG} \rightarrow \mathrm{GA}$. The results indicate that the hybrid algorithm is $76 \%$ faster than the GA alone and is more precise than using the RSM alone in the application model.

Before applying the new algorithm, the effectiveness for the test functions was exemplified, and the optimized design in the SPM motor produced clear advantages in the end.

\section{Acknowledgments}

This research was supported by a grant (Code07 Next Generation High Speed Train A01) from the Railroad Technology Development Program (RTDP) funded by the Ministry of Land, Transport, and Maritime Affairs of the Korean government.

\section{References}

[1] Yubo Yang, "Study of Magnet Asymmetry for Reduction of Cogging Torque in Permanent Magnet Motors", Industrial Electronics and Applications, 2009. ICIEA 2009. 4th IEEE Conference, pp. 2325-2328, May 2009.

[2] Hyun Kook Yi, Comparison of Experimental Design and Evolution Strategy for Optimal Design of BLDC Motor, M.A. Thesis, Pusan National University 2004.
[3] Jae Seok Choi, Hong Sik Kim, Jun Min Cha and Roy Billinton, "Nodal Probabilistic Congestion and Reliability Evaluation of a Transmission System under the Deregulated Electricity Market", Proceedings of IEEE PES SM2001 Conference, Vancouver, Canada, July 2001.

[3] Chang-Eob Kim, "Optimum Design of BLDC Motor Magnet Using Genetic Algorithm and Response Surface Method", Journal of the Korean Institute of Illuminating and Electrical Engineers, Vol. 18, No. 6, pp. 152-157, November 2004.

[4] Laurent Jolly, M. A. Jabbar, Liu Qinghua, "Design Optimization of Permanent Magnet Motors Using Response Surface Methodology and Genetic Algorithms", IEEE Transactions on Magnetics, pp.91-92, Vol. 41, No. 10, 2005

[5] Seong Hyun Woo, (A) study on the permanent magnet pole shape optimization for BLDC motor by using the LHS, M.A., HONGIK University, 2004.

[6] Hee Sung Yoon, "Shape Optimization of DC Solenoid Valve to Minimize the Time of Action Using Response Surface Method", The Trans. of KIEE, Vol. 55-B, No. 9, pp. 449-458, Sep 2006.

[7] Nicola Bianchi and Silverio Bolognani, "Design Techniques for Reducing the Cogging Torque in Surface-Mounted PM Motors", IEEE Transactions on Industry Applications, Vol. 38, No. 5, Sept.-Oct. 2002.

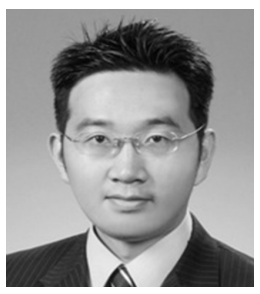

Min-Jae Kim received his B.S in electrical engineering from Seoul National University. His research interests are numerical analysis and design of electrical machines.

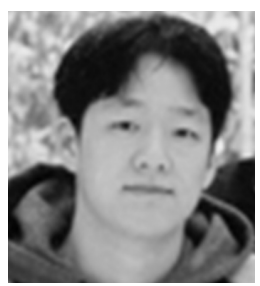

Jaewon Lim received his B.S in electrical engineering from Seoul National University. His research interests are numerical analysis and design of electrical machines.

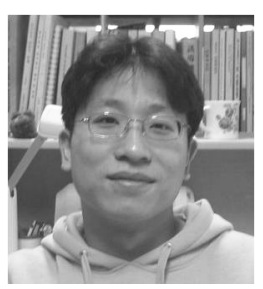

Jang-Ho Seo received his B.S degree in electrical engineering from ChoongAng University. His research interests are numerical analysis and design of electrical machines.

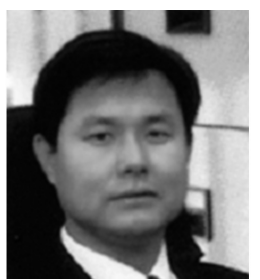

Hyun-Kyo Jung received his Ph.D. in electrical engineering from Seoul National University. His research interests are electric machinery, EM waves, and circuit breakers, among others. 